\title{
TITLE:
}

\section{A Wenner-Gren Symposium: The Great Apes Revisited}

AUTHOR(S):

Nishida, Toshisada

CITATION:

Nishida, Toshisada. A Wenner-Gren Symposium: The Great Apes

Revisited. Pan Africa News 1995, 2(1): 11-11

ISSUE DATE:

1995-06

URL:

http://hdl.handle.net/2433/143311

RIGHT:

Copyright (C) Pan Africa News. 


\section{A Wenner-Gren Symposium: The Great Apes Revisited}

\author{
Toshisada Nishida
}

The Wenner-Gren symposium of the Great Apes Revisited organized by Bill McGrew and myself was held at Hotel Cabo San Lucas of Baja California, Mexico between November 12 and 19, 1994. Participants were Christophe Boesch, Barbara Fruth, Diane Doran, Jane Goodall, Charlotte Hemelrjik, Takayoshi Kano, Suehisa Kuroda, Linda Marchant, Tetsuro Matsuzawa, John Mitani, Jim Moore, Sue Savage-Rumbaugh, Carel van Schaik, Caroline Tutin, Frans de Waal, David Watts, Frances White, Richard Wrangham, Juichi Yamagiwa and Adrienne Zihlman, in addition to the organizers and the President of WGF, Sydel Silverman and her staff, Laurie and Mike.

The outline of the symposium will be reported by Linda Marchant in Current Anthropology in the near future and an anthology of the spoken papers will

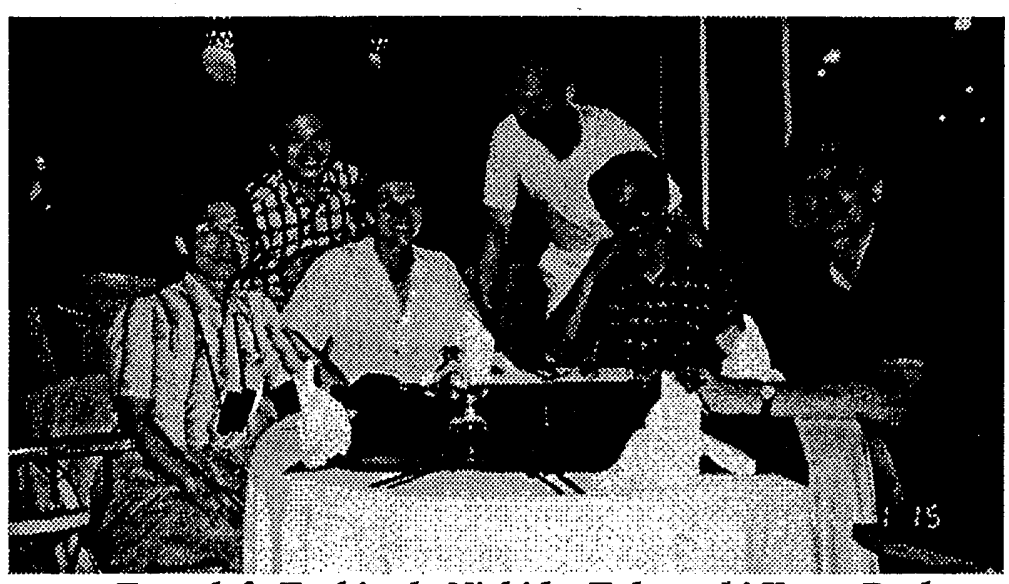

From left, Toshisada Nishida, Takayoshi Kano, Barbara Fruth, William C. McGrew, Tetsuro Matsuzawa, and Frans B. M. de Waal.

be published by August 1996.

Caroline recited her limericks just before the farewell dinner in the evening of November 18. Sue completed to write her own after she returned to Atlanta. These two lovely pieces of limericks are reproduced here with the permission of the authors. 